\title{
Non-disabled Space Invaders! A Study Critically Exploring the Scholarly Reporting of Research Attributes for Persons With and Without Disability
}

\author{
DAMIAN MELLIFONT \\ University of Sydney, Australia
}

\begin{abstract}
Social justice requires that the "nothing about us without us" disability inclusion mantra not be rejected or watered down in knowledge production activities. Appreciating the need for a greater representation of disability in these activities, this investigative study aims to (a) determine if there is a statistically significant difference in the median research attribute reporting scores between articles whose content refers to the term "researchers with lived experience" and articles whose content refers to "non-disabled researchers," and (b) to critically discuss how the scholarly literature reports on the attributes of researchers with and without disability. Enabling this exploration, this study has applied the Mann-Whitney $U$ test and thematic analysis to a purposive sample of 20 articles that were retrieved from a Scopus database search. Findings reveal that the median score of reported research attributes was statistically significantly higher in the group of articles whose content referred to the term researchers with lived experience than in the articles that referred to non-disabled researchers. Results also highlight attributes of empathy, ability, rigor and activism that are reportedly shared across the two groups of articles. Crucially, attention is given to a theme reported as unique to the researchers with disability group. This is the attribute of having firsthand knowledge of disability (i.e., lived experience). The study concludes by recognising that lived experience, when incorporated throughout the research process, can help to redress deficiencies that might otherwise be present.
\end{abstract}

KEYWORDS researchers with disability; lived experience-led research; emancipatory research; social inclusion 


\section{Introduction}

The lived experiences of people with disability should not be undervalued. Indeed, a need for the significant participation of people with disability is progressively being acknowledged throughout areas of research, policy, and service development (Sin \& Fong, 2010). Recognising a need for such inclusion, it is appropriate to firstly differentiate between "disability studies" and "disability research." Clarifying the term disability studies is not straightforward. Ferguson and Nusbaum (2012) advise that coinciding with increasing use of the term is a growing confusion as to its meaning. Söder (2009) offers both narrow and wide definitions of disability studies. Defined narrowly, disability studies refers to research conducted in deliberate support of political activism by people with disability (Söder, 2009). This research often challenges the traditional medical model of disability, and attempts to reduce the medicalisation of persons with disability and the "pathologizing of difference" (Linton, 1998, p. 527).

The wider field of disability studies - often called disability research - is less motivated by political activism, and more concerned with developing a social sciences-based understanding of disability (Söder, 2009). It is steeped in medical model ideology and influence (Strandberg, Möller, \& Widén, 2017). For example, Barnes (2001) suggests that the majority of disability research in the UK was funded by government agencies, including the Medical Research Council and the Department of Health, which were controlled by medical interests and adhered to medical model assumptions concerning disability. It is reasonable to infer, therefore, that non-disabled researchers and medically endorsed topics have historically dominated the disability research agenda. Disability studies, as a sub-field within disabilities research, emerged from criticisms by members of the disability people's movement (Barnes, 2001) of this medical orientation toward disability within the wider field of disability research. Disability studies - narrowly defined endorses a shift away from medically-dominated research and towards research inclusive of researchers with disabilities.

Disability inclusion involves a participatory or emancipatory approach to conducting studies. Sohng (1996, p. 81) describes participatory research as "a means of preventing an elite group from exclusively determining the interests of others, in effect of transferring power to those groups engaged in the production of popular knowledge." A key strength of participatory methods is their capacity to investigate local perceptions and knowledge (Cornwall \& Jewkes, 1995), and enable participants to become co-researchers (Balcazar, Keys, Kaplan, \& Suarez-Balcazar, 1998). According to Martin (2015, p. 211), "emancipatory research is achieved when the social relations of research production are more enabling or 'emancipatory'." This style of research moves away from performing studies on people to doing studies with people (Department of Health, 2005, cited in Doody, 2018). In keeping with the values of inclusive research, all researchers including those with 
disabilities need to be involved from the start (Strnadová, Cumming, Knox, Parmenter \& Welcome to Our Class Research Group, 2014). Woelders, Abma, Visser and Schipper (2015) note that emancipatory research has a political objective in addition to knowledge production. In this context, Beresford (2002) argues that emancipatory research developed from concerns by service user groups about the purpose of research and who controls it. Within the rubric of emancipatory research, studies should be co-produced with participants, and opportunities should exist for researchers with disability to take on leadership roles across a range of study activities (Beresford, 2002; Voronka, 2016). Unfortunately, despite ample capacity for disability researcher participation in user-led and co-produced studies, such studies are seldom conducted. Banas, Magasi, The and Victorson (2019) caution that there is an overall shortage of people with disability operating in the research establishment. Mellifont et al. (2019) also note that lived experience expertise has not received the authority that it warrants.

Notable barriers challenge ambitions to conduct more lived experience led and co-produced research: even highly qualified disabled persons may find it difficult to obtain academic positions that would allow them to conduct research (Kirkham, Webster, Chen \& Vines, 2016; harsh rejection criteria might exclude persons with complicated disabilities from joining study teams (Banas et al., 2019); mobility of prospective disabled researchers is complicated by transport and building inaccessibility; participation of persons with emotional, social or cognitive impairments can be impeded by crowds and noise (Banas et al., 2019); and "research skills training still remains mostly ignored in inclusive disability research literature" (Strnadová et al., 2014, p.14). More broadly, Solis (2006) recognises the need to challenge ableism-driven prejudice, discrimination and exclusion in order to facilitate inclusive disability research. Denying persons with lived experience access to research activity might on occasion be "deliberate and strategic" (Moore, Beazley \& Maelzer, 1998, p. 59 cited by Bricher, 2000).

Mladenov (2016, p. 1228) makes the important observation, "a society is just only when it enables all of its adult members to interact with each other as peers, and this necessarily includes disabled people." Recognising that the barriers to research inclusion inhibit social justice (in the form of epistemic justice - "nothing about us without us") and appreciating that a greater representation of lived experience is required in order to combat this injustice, it is a timely research exercise to explore how the scholarly literature reports on the attributes of researchers with and without disability.

This investigation explores the ways in which scholarly articles report about research attributes in relation to researchers with and without disability. Collectively these attributes of researchers, as derived from the literature, include: researcher abilities to conduct studies; knowledge stemming from lived experiences with disability; empathy for disability; capacity to support disability activism; and the contribution of research rigor (Birken \& Harper, 2017; Callus, 2019; Mellifont et al., 2019; Strnadová et al., 2014). I 
investigate possible differences between the median research attribute reporting scores as recorded for two groups of articles (the first group primarily focusing on researchers with disability and the second on nondisabled researchers). The term "research attribute reporting score" is simply a count of researcher attributes as derived from a scholarly article. The median research attribute reporting scores are thus the median values of researcher attribute counts for each of the two groups of articles. The Mann Whitney $U$ test is used to test for differences in the medians of these two groups. Crucially, in addition to undertaking this quantitative assessment the study critically examines each of the researcher attribute themes in terms of their alignment with disabled and non-disabled researcher groups. Hence, the study aims to: (a) determine if there is a statistically significant difference in the median research attribute reporting scores between articles whose content refers to the term researchers with lived experience and articles whose content refers to non-disabled researchers; and (b) critically discuss how the scholarly literature reports on the attributes of researchers with and without disability.

\section{Method}

In order to identify the groups of articles referring to the attributes of researchers with and without disability, two Scopus database searches were conducted. The search term used to populate the first group of articles was: ("researcher* with disability" OR "researcher* with lived experience") AND NOT ("non-disabled researcher*"). The second search term applied was "non-disabled researcher*" AND NOT ("researcher* with disability"). The inclusion criteria applied for both searches was: years = all years; document type $=$ article; fields $=$ search all fields; article is accessible (i.e., a full version of the article is available for download); and article describes attribute(s) of researchers with or without disability respectively. Findings of these searches were recorded in two analytical tables (see Table 1 and Table 2). Details of each relevant article include: the article ID; the group to which the article is uniquely aligned (i.e., groups discuss research attributes of researchers with or without disability respectively); the count of attributes identified; the attribute labels; and supporting quotes. Reflecting the application of thematic analysis, coding rules were created and used to assign quotes to illustrate their respective themes (i.e., attribute labels). The search strategy was purposefully designed to provide a sample that, while modest in size, would meet the analytical needs of this exploratory study. The study design also met assumptions for conducting the Mann-Whitney U test for differences between groups of data. Specifically, there was one dependent variable (i.e., research attribute reporting scores), one independent variable that contains two independent groups (i.e., articles whose content refers to the term researchers with lived experience and articles whose content refers to non-disabled 
researchers), and the groups were unique in the sense that an article could not belong in both groups. The Mann-Whitney $U$ test is appropriate for determining if differences exist between two groups as based upon a continuous dependent variable (Laerd Statistics, 2018). In order to achieve the first of the study aims, the nonparametric Mann-Whitney $U$ test was undertaken to test whether the median scores of the dependent variable were different for two independent groups. Nonparametric tests are statistical enquiries that do not require a normal distribution of data (University of New England, 2000). Group 1 was represented by articles whose content referred to the research attributes of researchers with disability, and group 2 was confined to articles referring to the research attributes of non-disabled researchers. A SPSS data file mirroring the fields and content of the analytical tables (i.e., article ID, group number and attribute count) was then created and populated. Finally, the Mann-Whitney U test was run in SPSS Statistics version 24 and the findings recorded.

\section{Results}

The first search term identified 11 possibly relevant articles with 10 of these remaining after applying the inclusion criteria. The second search term revealed 124 possibly relevant articles with the first 10 relevant articles purposefully selected to enable matching group sizes. Thematic analysis results for articles reporting on the attributes of researchers with and without disability are displayed in Tables 1 and 2. Each table describes the Article ID, group number, count of unique attributes reported, and quotations to support the attributes that were captured. To promote data transparency and research rigor, Table 3 provides readers with the attribute coding rules that were applied.

A Mann-Whitney $U$ test was conducted to determine if there is a statistically significant median difference in the reporting of research attributes between article groups 1 and 2 . The test revealed that group 1 (i.e., articles whose content explicitly referred to the terms researcher(s) with disability or lived experience had a mean score of 13.80). Group 2 (i.e., articles whose content referred to the term non-disabled researchers) had a mean score of 7.20. The result was statistically significant as the exact $p$ value $(\mathrm{p}=.011)$ is less than .05 . 


\begin{tabular}{|c|c|c|c|c|}
\hline $\begin{array}{l}\text { Article } \\
\text { ID }\end{array}$ & Group & Count & Attributes & Supporting quotes \\
\hline 1.00 & 1 & 2 & $\begin{array}{l}\text { ability } \\
\text { knowledge }\end{array}$ & $\begin{array}{l}\text { "A third account, from a neurodiverse } \\
\text { researcher, described how their } \\
\text { accommodated anxiety, rather than } \\
\text { constraining their performance, was a } \\
\text { driver of their academic achievements } \\
\text { (Mellifont et al., 2019, p. 12). } \\
\text { "One narrative spoke about how their } \\
\text { lived experience with a neurological } \\
\text { condition that provided them with } \\
\text { 'extensive' knowledge in an area of } \\
\text { importance to research was being } \\
\text { overlooked" (Mellifont et al., 2019, p. } \\
\text { 12). }\end{array}$ \\
\hline 2.00 & 1 & 2 & $\begin{array}{l}\text { empathy } \\
\text { activism }\end{array}$ & $\begin{array}{l}\text { "Indeed, this co-researcher took the } \\
\text { responsibility to care for herself and other } \\
\text { invitees with lived experiences" (Groot, } \\
\text { Vink, Haveman, Huberts, Schout \& } \\
\text { Abma, 2019, p. 294). } \\
\\
\text { "I noticed that some co-researchers with a } \\
\text { lived experience felt a moral duty to solve } \\
\text { problems in health care for one's peers" } \\
\text { (Groot et al., 2019, p. 297). }\end{array}$ \\
\hline 3.00 & 1 & 1 & activism & $\begin{array}{l}\text { "He was a highly vocal advocate of } \\
\text { disability rights and was becoming a } \\
\text { successful researcher and budding } \\
\text { entrepreneur" (Kirkham et al., 2016. pp. } \\
\text { 71-72). }\end{array}$ \\
\hline 4.00 & 1 & 2 & $\begin{array}{l}\text { knowledge } \\
\text { empathy }\end{array}$ & $\begin{array}{l}\text { "Peer researchers were important for this } \\
\text { study as their shared experiences of } \\
\text { homelessness provided expert insider } \\
\text { knowledge and access to a 'hard to reach' } \\
\text { population group in a short period of time } \\
\text { (Elliott, Watson \& Harries, 2002)" } \\
\text { (Massie, Machin, McCormack \& Kurth, } \\
\text { 2018, p. 344). } \\
\text { "the use of peer researchers (compared to } \\
\text { academic researchers) can offer a more } \\
\text { equal power balance between researcher } \\
\text { and participant, thus participants may feel } \\
\text { more comfortable to provide open and } \\
\text { honest accounts (Burns and Schubotz, } \\
\text { 2009)" (Massie et al., 2018, p. 344). }\end{array}$ \\
\hline
\end{tabular}




\begin{tabular}{|c|c|c|c|c|}
\hline 5.00 & 1 & 3 & $\begin{array}{l}\text { knowledge } \\
\text { ability } \\
\text { rigor }\end{array}$ & $\begin{array}{l}\text { "Having an interviewer with lived } \\
\text { experience has advantages as they are } \\
\text { familiar with the realities of the topic } \\
\text { being examined, unlike researchers } \\
\text { without lived experience, who may have } \\
\text { blind spots regarding the context of the } \\
\text { topic (Devotta et al., 2016)" (Birken \& } \\
\text { Harper, 2017, p. 410). } \\
\text { "Both authors have extensive experience } \\
\text { of carrying out interviews in the context } \\
\text { of research and have received training in } \\
\text { interviewing skills" (Birken \& Harper, } \\
2017, \text { p. } 410 \text { ). } \\
\text { "Entwhistle and colleagues (1998) } \\
\text { recommend this approach of involving } \\
\text { service users at this stage of the research } \\
\text { process to enhance the robustness of both } \\
\text { the implications and conclusions of the } \\
\text { study" (Birken \& Harper, 2017, p. } 410 \text { ). }\end{array}$ \\
\hline 6.00 & 1 & 2 & $\begin{array}{l}\text { rigor } \\
\text { ability }\end{array}$ & $\begin{array}{l}\text { "Peer participation in research increases } \\
\text { relevance, and assists in more culturally } \\
\text { appropriate data collection, analysis, and } \\
\text { dissemination (Coser et al., 2014)" } \\
\text { (Mitchell, Durante, Pellatt, Richardson, } \\
\text { Mathias \& Buxton, 2017, n.p.) } \\
\text { "Two peer researchers with lived } \\
\text { experience of THN were recruited from } \\
\text { ICY and were involved in all phases of } \\
\text { the study" (Mitchell et al., 2017, n.p.) }\end{array}$ \\
\hline 7.00 & 1 & 2 & $\begin{array}{l}\text { ability } \\
\text { knowledge }\end{array}$ & $\begin{array}{l}\text { "A co-researcher with lived experience } \\
\text { took part in all stages of the study" } \\
\text { (Biringer, Davidson, Sundfør, Ruud \& } \\
\text { Borg, 2016, n.p.) } \\
\text { "However, active participation by the } \\
\text { coresearcher with experience as a service } \\
\text { user during the interviews and analysis } \\
\text { helped the researchers with professional } \\
\text { backgrounds to better understand what } \\
\text { participants were trying to communicate" } \\
\text { (Biringer et al., 2016, n.p.) }\end{array}$ \\
\hline 8.00 & 1 & 1 & knowledge & $\begin{array}{l}\text { "They did not refer to my impairment } \\
\text { during the present interviews, but this } \\
\text { knowledge may have facilitated their } \\
\text { statements about the importance of } \\
\text { functional recovery" (Tagaki, 2016, p. 4) }\end{array}$ \\
\hline
\end{tabular}




\begin{tabular}{|c|c|c|c|c|}
\hline 9.00 & 1 & 5 & $\begin{array}{l}\text { ability } \\
\text { rigor } \\
\text { activism } \\
\text { empathy }\end{array}$ & $\begin{array}{l}\text { "At least half the questions used in the } \\
\text { final protocol did not occur to the } \\
\text { academic researchers, as they did not have } \\
\text { the lived experience that their colleagues } \\
\text { had... The researchers with intellectual } \\
\text { disabilities also added more specific } \\
\text { questions to those developed by the } \\
\text { academic researchers." (Strnadová et al., } \\
2014, \text { p. 19). } \\
\text { "...Each team member's unique skills and } \\
\text { contributions came to light over the } \\
\text { course of time" (Strnadová et al., 2014, p. } \\
\text { 16). } \\
\text { "Gradually, the researchers with } \\
\text { intellectual disabilities began to contribute } \\
\text { to the research with their own research } \\
\text { agenda" (Strnadová et al., 2014, p .17). } \\
\text { "The researchers with intellectual } \\
\text { disabilities mentioned diverse reasons for } \\
\text { becoming a part of research team, ranging } \\
\text { from wishing to learn something new to a } \\
\text { desire to help others" (Strnadová et al., } \\
2014, \text { p. 17). } \\
\text { "RID2 is very empathetic, polite and } \\
\text { caring to others, which positively } \\
\text { influences the whole group's atmosphere" } \\
\text { (Strnadová et al., 2014, p. 20). }\end{array}$ \\
\hline 10.00 & 1 & 3 & $\begin{array}{l}\text { activism } \\
\text { ability } \\
\text { knowledge }\end{array}$ & $\begin{array}{l}\text { "I have discovered that many of my } \\
\text { conversations with other doctoral students } \\
\text { about disability center on hope and } \\
\text { support for disabled people" (Solis, 2006, } \\
\text { p. 151). } \\
\text { "Their perception of me as a productive } \\
\text { and contributing member of society } \\
\text { automatically negates my disabilities" } \\
\text { (Solis, 2006, p. 151). } \\
\text { "To be meaningful and informative, } \\
\text { disability narratives should be based on } \\
\text { the experiences of disabled people, rather } \\
\text { than on the imposition of normalizing, } \\
\text { medically-based values, for example... the } \\
\text { professionalization of disability studies } \\
\text { should not overlook the fact that there is a }\end{array}$ \\
\hline
\end{tabular}




\begin{tabular}{|l|l|l|}
\hline & & $\begin{array}{l}\text { distinction between those who speculate } \\
\text { about what it means to be disabled and } \\
\text { those of "us" who actually live as disabled } \\
\text { individuals. This distinction is important } \\
\text { because people with disabilities should } \\
\text { speak for themselves about their own } \\
\text { experiences." (Solis, 2006, p. 153). }\end{array}$ \\
\hline
\end{tabular}

Table 1. Researchers with disability attribute(s)

\begin{tabular}{|c|c|c|c|c|}
\hline $\begin{array}{l}\text { Article } \\
\text { ID }\end{array}$ & Group & Count & Attributes & Supporting quotes \\
\hline 11.00 & 2 & 1 & activism & $\begin{array}{l}\text { "Using research to stimulate change in } \\
\text { societal perceptions of women with } \\
\text { disabilities, and raising awareness of their } \\
\text { situations, especially their experiences of } \\
\text { GBV, requires action from both disability } \\
\text { and non-disability sectors" (van der } \\
\text { Heijden, Harries, \& Abrahams, 2019, p. } \\
\text { 745). }\end{array}$ \\
\hline 12.00 & 2 & 2 & $\begin{array}{l}\text { activism } \\
\text { empathy }\end{array}$ & $\begin{array}{l}\text { "As a non-disabled academic, I am also } \\
\text { aware that my work in disability studies is } \\
\text { like that of an activist working for } \\
\text { disabled people's rights" (Callus, 2019, p. } \\
\text { 1). } \\
\text { "Among the challenges faced by the } \\
\text { academic researcher who is trying to be } \\
\text { inclusive are the control exerted by non- } \\
\text { disabled adults on the lives of } \\
\text { people with intellectual disability and the } \\
\text { provision of support for people with } \\
\text { intellectual disability to engage with } \\
\text { research" (Callus, 2019, p. 6). }\end{array}$ \\
\hline 13.00 & 2 & 1 & ability & $\begin{array}{l}\text { "Disability scholars contribute ability to } \\
\text { this list of systems perpetuating } \\
\text { inequalities of power..." (Mitchell, } \\
\text { Boettcher-Sheard, Duque \& Lashewicz, } \\
\text { 2018, p. 674). }\end{array}$ \\
\hline 14.00 & 2 & 1 & rigor & $\begin{array}{l}\text { "...the accountability of the disabled } \\
\text { researchers to the non-disabled } \\
\text { researchers and vice versa..." (Stone \& } \\
\text { Priestley, } 1996 \text { cited in Chow et al., 2017, } \\
\text { p. 723). }\end{array}$ \\
\hline
\end{tabular}




\begin{tabular}{|c|c|c|c|c|}
\hline 15.00 & 2 & 1 & empathy & $\begin{array}{l}\text { "Recruiting people with intellectual } \\
\text { disabilities as participants in research is } \\
\text { increasingly recognised as important by } \\
\text { people with intellectual disabilities } \\
\text { themselves as well as by academics" } \\
\text { (McDonald \& Kidney, 2012; Walmsley, } \\
2004 \text { cited in Carey \& Griffiths, 2017, p. } \\
\text { 202). }\end{array}$ \\
\hline 16.00 & 2 & 1 & rigor & $\begin{array}{l}\text { "However, I do believe that there is also } \\
\text { value in research when non-disabled } \\
\text { academics (such as myself) reflect on } \\
\text { these viewpoints and interpret them from } \\
\text { their own position" (Callus, 2019, p. 2). }\end{array}$ \\
\hline 17.00 & 2 & 1 & empathy & $\begin{array}{l}\text { "This paper argues that the principles of } \\
\text { emancipatory research can apply to } \\
\text { research that involves a non-disabled } \\
\text { researcher working alongside service } \\
\text { users" (Martin, 2015, p. 209). }\end{array}$ \\
\hline 18.00 & 2 & 1 & activism & $\begin{array}{l}\text { "Nothing about us without us' is a } \\
\text { perfectly legitimate rallying call and } \\
\text { principle of political participation. But it } \\
\text { should not end up in disqualifying all non- } \\
\text { disabled voices" (Sherlaw \& Hudebine, } \\
\text { 2015, p. 15). }\end{array}$ \\
\hline 19.00 & 2 & 1 & empathy & $\begin{array}{l}\text { "From the research tradition, there has } \\
\text { been a growing interest in emancipatory } \\
\text { and participatory approaches..." } \\
\text { (Walmsley, } 2001 \text { cited in Sin \& Fong, } \\
\text { 2010, p. 13). }\end{array}$ \\
\hline 20.00 & 2 & 2 & $\begin{array}{l}\text { empathy } \\
\text { ability }\end{array}$ & $\begin{array}{l}\text { "he argues in favour of non-disabled } \\
\text { researchers engaging 'as allies to disabled } \\
\text { people in disability studies' (Duckett, } \\
\text { 1998, p. 627)" (Macbeth, 2010, p. 479). } \\
\text { "This argument is even more pertinent to } \\
\text { disability research in sport and leisure } \\
\text { settings, which is underdeveloped and } \\
\text { currently conducted by a relatively small } \\
\text { number of disabled and non-disabled } \\
\text { researchers" (Macbeth, 2010, p. 482). }\end{array}$ \\
\hline
\end{tabular}

Table 2. Non-disabled researchers' attribute(s) 


\begin{tabular}{|l|l|}
\hline Attribute & Coding rule \\
\hline ability & $\begin{array}{l}\text { Articles describe the abilities of either individuals with lived } \\
\text { experience or non-disabled persons to conduct research. }\end{array}$ \\
\hline knowledge & $\begin{array}{l}\text { Articles describe the knowledge benefits to research that comes from } \\
\text { personal experience with disability. }\end{array}$ \\
\hline empathy & $\begin{array}{l}\text { Article describes capacity for either individuals with lived experience } \\
\text { or non-disabled persons to display empathy for disability. }\end{array}$ \\
\hline rigor & $\begin{array}{l}\text { Article describes capacity for either individuals with lived experience } \\
\text { or non-disabled persons to contribute to research rigor. }\end{array}$ \\
\hline activism & $\begin{array}{l}\text { Article describes capacity for either individuals with lived experience } \\
\text { or non-disabled persons to support disability activism. }\end{array}$ \\
\hline
\end{tabular}

Table 3. Attribute coding rules

\section{Discussion}

This research reveals that the median score of reported research attributes was statistically significantly higher in articles whose content referred to the term "researchers with lived experience" than in articles referring to "nondisabled researchers." This finding is important as it indicates that the scholarly literature is recognising the various capabilities of researchers with disability. Nonetheless, it is also appropriate to acknowledge that most of the attributes reported are not unique to any one group. In this section, I discuss how shared attributes of empathy, ability, rigor and activism were reported for researchers across each of the two groups of articles. I focus on the single attribute that was uniquely reported in the researchers with disability group: having firsthand knowledge of disability (i.e., lived experience).

Researchers with disability are reported as having capacity to display empathy towards researchers with lived experiences and other team members (Groot et al., 2019; Strnadová, et al., 2014). This attribute of empathy offers practical research benefits. Burns and Schubotz (2009), as cited in Massie et al. (2018, p. 344), suggest that the application of peer researchers (as opposed to "academic researchers") can help to balance the power between researcher and study participants and potentially encourage more truthful responses. However, it should not be assumed that all researchers with disability will necessarily be empathic in nature or inevitably hold any other attribute as reported in this paper. Further, when reporting about researchers with disability, care should be taken to avoid making assumptions about lack of formal qualifications. Comparing peer researchers to academic researchers overlooks the possibility that peer researchers (i.e., researchers who have lived experience with the disability study subject at hand) might also be highly qualified academically (e.g., qualified at a $\mathrm{PhD}$ level). In reporting about the empathy displayed by researchers without disability, topics focused on inclusion and the co-production of research where non-disabled and 
researchers with lived experience work together as partners (Callus, 2019; Duckett, 1998 cited in Macbeth, 2010; Martin, 2015; Walmsley, 2004 cited in Carey, 2017). This academic support for co-produced studies is welcome, but greater scholarly emphasis is nevertheless needed on the capacity of researchers with disability who are qualified through formal education or experience to lead research teams.

Scholarly reporting highlights the abilities of researchers with disability. For example, Mellifont et al. (2019) raise the prospect of accommodated neurodiversity (e.g., anxiety) driving rather than limiting academic performance. Moreover, the literature indicates that scholars with lived experience have capacity to participate across all stages of research (Biringer et al., 2016; Mitchell et al., 2017), even though particular abilities are not always immediately recognised. Strnadová et al. (2014) notes how the research skills and offerings of team members can eventually surface. Critically, occasions where these skills might be initially absent should not be used as an excuse to dismiss lived experience research participation; researchers with disability can receive training in research skills such as interviewing (Birken \& Harper, 2017). Reporting on the underdeveloped field of disability studies in sport and leisure, Macbeth (2010) recognises the contributions of researchers, including those without disability. Even so, another article from group 2 commented, "disability scholars contribute ability to this list of systems perpetuating inequalities of power..." (Mitchell et al., 2018, p. 674). Academic reporting, as indicated above, suggests that people with lived experience can have research abilities or develop these skills if needed to actively participate and contribute to disability literature. Such ability and potential should not be dismissed or downplayed, but rather recognised in promoting a greater investment in lived experience-led and coproduced studies. Future research is needed to examine the possible extent to which ableism, sanism or other types of disability discrimination (e.g., audism) are contributing to a perverse status quo of lived experience underrepresentation in knowledge production about disability. These "isms" might contribute to the social and economic exclusion of researchers with disability from participating to their full potential in the academy and elsewhere.

Researchers with lived experience can add to the rigor of academic investigations. In this regard, one of the articles commented on how the inclusion of service user researchers in the analysis stage can improve the strength of study propositions and conclusions:

The first author, who did the analysis, has experience of and training in the use of qualitative research methods, including data analysis. The second author was involved in interpreting the findings. Entwhistle and colleagues (1998) recommend this approach of involving service users at this stage of the research process to enhance the robustness of both the implications and conclusions of the study. (Birken \& Harper, 2017, p.410) 
The contributions of researchers with disability to academic rigor and integrity is not confined to the analytical phase of the research lifecycle. The participation of peer researchers enhances research relevance as well as promoting the collection, analysis and diffusion of culturally appropriate data (Coser et al., 2014, cited in Mitchell et al., 2017). Strnadová et al. (2014) recognise that researchers with lived experience (intellectual disabilities in this case) can further investigations through their specific study agenda. Future research is required to examine the degree to which research integrity is advanced by empowering more researchers with lived experience to set and control the direction of research enquiry. Concepts of academic rigor and control are also included in the scholarly reporting of non-disabled researchers. However, qualifications appear to be attached to the level of control that is awarded to lived experience researchers through notions of reciprocated accountability and non-disabled reflection and interpretation. In terms of reciprocated accountability, Stone and Priestly (1996) as cited in Chown et al. (2017), speak of the accountability of researchers with disability to non-disabled investigators as well as the answerability of non-disabled researchers to those with lived experience. With regard to non-disabled reflection and interpretation, Callus (2019) supports the value of non-disabled researchers considering perspectives and understanding them via their personal outlook. Acknowledging this position, it is vital to recognise that the considerations of non-disabled researchers do not occur in an ideologically or politically-free vacuum.

Included among the articles reporting on researchers with disability was the concept of activism-oriented research (AOR). For example, particular coresearchers with disability were depicted as feeling morally obliged to resolve health service issues for peers (Groot et al., 2019). Strnadová et al. (2014) also describes an aspiration to assist others as one of the motives for investigators with intellectual disabilities to join a research team. Further, Solis (2006) reports on conversations of a doctoral candidate with disability with other doctoral students, which focus upon supporting people with disability. AOR was also present in articles reporting on non-disabled researchers. van der Heijden et al. (2019) wrote about how studies to encourage a change in social perceptions concerning women with disability needs involvement from disability and non-disability areas alike. In addition to collective action, support for non-disabled AOR is evident at a personal level:

Given the centrality of disabled people's perspectives and actions in matters concerning them, the role of the non-disabled person in activism and academia has been much debated. I myself am a non-disabled academic, and my main area of interest is means of empowerment for people with intellectual disability, including through self-advocacy and inclusive research. (Callus, 2019, p. 2)

The literature also attempts to qualify the disability inclusion motto of "nothing about us without us" from an AOR perspective. Sherlaw and 
Hudebine (2015, p. 15), in recognising this motto as a genuine call to rally, nonetheless note that the call should not disqualify all non-disabled opinions in disability politics.

One attribute was identified as unique to the researchers with disability group. Seven out of the 10 articles from this group revealed the attribute of lived experience knowledge. Mellifont et al. (2019) spoke of how lived experience with a neurological disability can offer vast knowledge. Furthermore, lived experience with disability can inform questions that might not be apparent to academic researchers without disability (Strnadová et al., 2014, p.19). While assisting to set research direction and inform study design, lived experience can also be beneficial across the data collection and analysis phases. Peer researchers can support swift access to a difficult-to-reach study population (Elliott, Watson \& Harries, 2002 cited in Massie et al., 2018). Interviewers with lived experiences have advantages in being aware of the realities of the research topic under investigation (Devotta et al., 2016 cited by Birken \& Harper, 2017). Moreover, according to Biringer et al. (2016, n.p.), the active involvement of service user co-researchers throughout data collection and analysis can assist researchers who have professional backgrounds to gain an improved understanding of what study participants are attempting to convey. Recognising the good intent of such reporting, researchers with lived experience and professional or academic researchers should not be simplistically referenced as mutual exclusive groups. These references are disrespectful to the persons who have lived experience and who also have experience in undertaking and successfully completing a $\mathrm{PhD}$. The following words challenge stigmatising, medical model ideology as applied to the field of disability research:

To be meaningful and informative, disability narratives should be based on the experiences of disabled people, rather than on the imposition of normalizing, medically-based values, for example. Second, the professionalization of disability studies should not overlook the fact that there is a distinction between those who speculate about what it means to be disabled and those of 'us' who actually live as disabled individuals. This distinction is important because people with disabilities should speak for themselves about their own experiences. (Solis, 2006, p. 153)

With these statements in mind, there needs to be a greater representation of PhD-qualified, lived experience researchers leading the way in knowledge production about disability.

\section{Limitations}

Being exploratory in nature, this unfunded study is limited to the search strategy that was purposefully applied. This strategy, broadly targeting articles referring to researchers with and without disability, does not explicitly seek out articles that might focus on particular types of disability 
(e.g., blind, deaf, neurodiverse). Investment is therefore needed in future research that utilises different search terms or additional databases. Such modifications to study design might identify attributes for researchers with and without disabilities that are not discussed in this initial investigation. Possibilities for other study designs to yield different median research attribute reporting scores to those revealed by this exploratory research is also acknowledged. Another limitation relating to the search strategy is that while each group of articles is confined to identifying research attributes of researchers with and without disabilities respectively, overlapping discussion of attributes involving these two groups was not possible. For example, it is recognised that an article discussing the attributes of non-disabled researchers might broadly reference researchers with lived experience (without referring to any of their research attributes).

\section{Conclusion}

Contributing to social justice literature, this research supports a message of inclusion. This message should be of particular interest to persons who are interested in advancing a greater involvement of researchers with disability. Crucially, this study reveals evidence challenging an ableist dismissal of lived experience in knowledge production activities. Scholarly reporting suggests that the research attributes as assigned to researchers with lived experience in no way falls short of those aligned with non-disabled academics. Importantly, researchers who have lived experiences with disability are reported as holding a distinct edge. For it is this attribute of lived experience that, when incorporated throughout the research cycle, can help to redress deficiencies that might otherwise be present. Reflecting the political nature of disability studies (Söder, 2009), research contributions by persons with lived experience can also target social justice outcomes. There needs to be a far greater representation of persons with lived experience who have the qualifications and abilities (or who can develop the necessary abilities) to lead or otherwise actively participate in research projects to their fullest extent. Such increased involvement reflects the true spirit of the "nothing about us without us" disability inclusion mantra.

\section{References}

Balcazar, F. E., Keys, C. B., Kaplan, D. L., \& Suarez-Balcazar, Y. (1998). Participatory action research and people with disabilities: Principles and challenges. Canadian Journal of Rehabilitation, 12, 105-112.

Banas, J. R., Magasi, S., The, K., \& Victorson, D. E. (2019). Recruiting and retaining people with disabilities for qualitative health research: Challenges and solutions. Qualitative Health Research, 29(7), 1056-1064. 
Barnes, C. (2001). 'Emancipatory' disability research: Project or process? Retrieved from https://disability-studies.leeds.ac.uk/wp-content/uploads/sites/40/library/Barnes-glasgowlecture.pdf

Beresford, P. (2002). User involvement in research and evaluation: Liberation or regulation?. Social policy \& Society, 1(2), 95-105.

Biringer, E., Davidson, L., Sundfør, B., Ruud, T., \& Borg, M. (2016). Experiences of support in working toward personal recovery goals: a collaborative, qualitative study. $B M C$ Psychiatry, 16(1), article 426. Retrieved from https://link.springer.com/article/10.1186/s12888-016-1133-x

Birken, M., \& Harper, S. (2017). Experiences of people with a personality disorder or mood disorder regarding carrying out daily activities following discharge from hospital. British Journal of Occupational Therapy, 80(7), 409-416.

Bricher, G. (2000). Disabled people, health professionals and the social model of disability: Can there be a research relationship?. Disability \& Society, 15(5), 781-793.

Burns, S., \& Schubotz, D. (2009). Demonstrating the merits of the peer research process: A Northern Ireland case study. Field Methods, 21(3), 309-326.

Callus, A. M. (2019). Being an inclusive researcher: seeking questions, raising answers. Disability \& Society, 34(7-8), 1241-1263.

Carey, E., \& Griffiths, C. (2017). Recruitment and consent of adults with intellectual disabilities in a classic grounded theory research study: Ethical and methodological considerations. Disability \& Society, 32(2), 193-212.

Chown, N., Robinson, J., Beardon, L., Downing, J., Hughes, L., Leatherland, J., Fox, K., Hickman, L., \& MacGregor, D. (2017). Improving research about us, with us: A draft framework for inclusive autism research. Disability \& Society, 32(5), 720-734.

Cornwall, A., \& Jewkes, R. (1995). What is participatory research? Social Science \& Medicine, 4l(12), 1667-1676.

Coser, L. R., Tozer, K., Van Borek, N., Tzemis, D., Taylor, D., Saewyc, E., \& Buxton, J. A. (2014). Finding a voice: participatory research with street-involved youth in the youth injection prevention project. Health Promotion Practice, 15(5), 732-738.

Department of Health, UK. (2005). Research governance framework for health and social care (2nd edition). Stationary Office, London: Department of Health.

Devotta, K., Woodhall-Melnik, J., Pedersen, C., Wendaferew, A., Dowbor, T. P., Guilcher, S. J., Hamilton-Wright, S., Ferentzy, P., Hwang, S., \& Matheson, F. I. (2016). Enriching qualitative research by engaging peer interviewers: A case study. Qualitative Research, $16(6), 661-680$.

Doody, O. (2018). Ethical challenges in intellectual disability research. Mathews Journal of Nursing \& Care, 1(1), 1-11.

Duckett, P. S. (1998). What are you doing here? 'Non disabled' people and the disability movement: A response to Fran Branfield. Disability \& Society, 13(4), 625-628.

Elliott, E., Watson, A. J., \& Harries, U. (2002). Harnessing expertise: Involving peer interviewers in qualitative research with hard-to-reach populations. Health Expectations, $5(2), 172-178$.

Entwistle, V. A., Renfrew, M. J., Yearley, S., Forrester, J., \& Lamont, T. (1998, Feb. 7). Lay perspectives: advantages for health research. Bmj, 316(7129), 463-466. Retrieved from https:/www.ncbi.nlm.nih.gov/pmc/articles/PMC2665609/pdf/9492683.pdf

Ferguson, P. M., \& Nusbaum, E. (2012). Disability studies: What is it and what difference does it make? Research \& Practice for Persons with Severe Disabilities, 37(2), 70-80.

Groot, B. C., Vink, M., Haveman, A., Huberts, M., Schout, G., \& Abma, T. A. (2019). Ethics of care in participatory health research: Mutual responsibility in collaboration with coresearchers. Educational Action Research, 27(2), 286-302.

Kirkham, R., Webster, M., Chen, K. L., \& Vines, J. (2016). Using disability law to expand academic freedom for disabled researchers in the United Kingdom. Journal of Historical Sociology, 29(1), 65-91.

Laerd Statistics. (2018) Mann-Whitney U test. Retrieved from https://statistics.laerd.com/features-tests.php

Linton, S. (1998). Disability studies/not disability studies. Disability \& Society, 13(4), 525-539. 
Macbeth, J. L. (2010). Reflecting on disability research in sport and leisure settings. Leisure Studies, 29(4), 477-485.

Martin, J. A. (2015). Research with adults with Asperger's syndrome - Participatory or emancipatory research?. Qualitative Social Work, 14(2), 209-223.

Massie, R., Machin, R., McCormack, F., \& Kurth, J. (2018). Having a voice: A collaborative research project exploring the challenges and assets of people experiencing homelessness. Journal of Integrated Care, 26(4), 342-352.

McDonald, K. E., \& Kidney, C. A. (2012). What is right? Ethics in intellectual disabilities research. Journal of Policy and Practice in Intellectual Disabilities, 9(1), 27-39.

Mellifont, D., Smith-Merry, J., Dickinson, H., Llewellyn, G., Clifton, S., Ragen, J., Raffaele, M., \& Williamson, P. (2019). The ableism elephant in the academy: A study examining academia as informed by Australian scholars with lived experience. Disability \& Society, 34(7-8), 1180-1199.

Mitchell, J., Boettcher-Sheard, N., Duque, C., \& Lashewicz, B. (2018). Who do we think we are? Disrupting notions of quality in qualitative research. Qualitative health research, 28(4), 673-680.

Mitchell, K., Durante, S. E., Pellatt, K., Richardson, C. G., Mathias, S., \& Buxton, J. A. (2017). Naloxone and the Inner City Youth Experience (NICYE): A community-based participatory research study examining young people's perceptions of the BC take home naloxone program. Harm Reduction Journal, 14(1), article 34. Retrieved from https://harmreductionjournal.biomedcentral.com/articles/10.1186/s12954-017-0160-3

Mladenov, T. (2016). Disability and social justice. Disability \& Society, 31(9), 1226-1241.

Moore, M., Beazley, S., \& Maelzer, J. (1998). Researching disability issues. Buckingham, UK: Open University Press.

Sherlaw, W., \& Hudebine, H. (2015). The United Nations Convention on the Rights of Persons with Disabilities: Opportunities and tensions within the social inclusion and participation of persons with disabilities. Alter, 9(1), 9-21.

Sin, C. H., \& Fong, J. (2010). Commissioning research, promoting equality: Reflections on the Disability Rights Commission's experiences of involving disabled children and young people. Children's Geographies, 8(1), 9-24.

Söder, M. (2009). Tensions, perspectives and themes in disability studies. Scandinavian journal of Disability Research, 11(2), 67-81.

Sohng, S. S. L. (1996). Participatory research and community organizers. Journal of Sociology \& Social Welfare, 23, 77-98

Solis, S. (2006). I'm "coming out" as disabled, but I'm "staying in" to rest: Reflecting on elected and imposed segregation. Equity \& Excellence in Education, 39(2), 146-153.

Stone, E., \& Priestley, M. (1996). Parasites, pawns and partners: Disability research and the role of non-disabled researchers. British Journal of Sociology, 47(4), 699-716.

Strandberg, T., Möller, K., \& Widén, S. (2017). Doctoral theses within the Swedish Institute for Disability Research 2000-2012: A review of content and interdisciplinarity. International Journal of Health Sciences, 5(2), 1-10.

Strnadová, I., Cumming, T. M., Knox, M., Parmenter, T., \& Welcome to Our Class Research Group. (2014). Building an inclusive research team: The importance of team building and skills training. Journal of Applied Research in Intellectual Disabilities, 27(1), 13-22.

Tagaki, M. (2016). Narratives of ambivalent meanings of acquired physical sisability in Japan. SAGE Open, 6(3), 1-11. Retrieved from https://journals.sagepub.com/doi/pdf/10.1177/2158244016666310

University of New England. (2000). Nonparametric tests. Retrieved from https://webstat.une.edu.au/unit_materials/c6_common_statistical_tests/nonparametric_test. html

van der Heijden, I., Harries, J., \& Abrahams, N. (2019). Ethical considerations for disabilityinclusive gender-based violence research: Reflections from a South African qualitative case study. Global Public Health, 14(5), 737-749.

Voronka, J. (2016). The politics of 'people with lived experience': Experiential authority and the risks of strategic essentialism. Philosophy, Psychiatry, \& Psychology, 23(3), 189-201. 
Walmsley, J. (2001). Normalisation, emancipatory research and inclusive research in learning disability. Disability \& Society, 16(2), 187-205.

Walmsley, J. (2004). Inclusive learning disability research: the (nondisabled) researcher's role. British Journal of Learning Disabilities, 32(2), 65-71.

Woelders, S., Abma, T., Visser, T., \& Schipper, K. (2015). The power of difference in inclusive research. Disability \& Society, 30(4), 528-542. 